\title{
CORRESPONDANCE
}

\section{A propos de l'Algérie en 1830. Réponse à P. Boyer ${ }^{1}$.}

M. l'archiviste P. Boyer critique deux de mes théories :

$1^{\circ}$ J'ai démontré que les Algériens, avant 1830, savaient généralement lire et écrire ${ }^{1}$. M. Boyer n'a trouvé aucun document qui infirme ceux que $j$ 'ai apportés. Je pourrais maintenant en citer d'autres, qui datent, non du $X \mathrm{VIII}^{\mathrm{e}}$ siècle, mais de la conquête française. Dans les procès-verbaux et rapports de la Commission d'Afrique de 1834 (p. 41) Bou Derba dit d la Commission qu'il serait utile de fonder un journal arabe, qui parlerait surtout d'industrie, d'agriculture et d'autres sciences utiles, car a presque tous les Arabes savent lire et écrire ". Dans un mémoire envoyé par le colonel WalsinEsterhazy en $1844^{\text {\& }}$ l'auteur, bon connaisseur de la societé algérienne, nous dit : "Vous serez peut-être étonné, monsieur que, chez un peuple réputé si barbare, la moyenne des individus du sexe masculin sachant lire et écrire soit au moins égale à celle que les statistiques départementales nous font connaître pour les habitants de nos campagnes... "Les chefs des Douairs et des Smelas lui ont offert de l'argent pour fonder un journal arabe, et le colonel préconise, sous l'égide française, la restauration de l'enseignement avec les anciens maîtres.

$20 \mathrm{~J}$ 'ai soutenu que l'Algérie, sans etre très riche, n'était pas plus pauvre que la plupart des autres pays méditerranéens à cette époque 4 . Des études plus approfondies méritent d'être faites sur chacun de ces pays pour établir des comparaisons. Pour l'instant $M$. Boyer n'apporte aucune contribution d ce probleme.

$3^{\circ} M$. Boyer me reproche d'avoir publié les mémoires de Thédenat en les présentant comme inédits. Il est vrai que $G$. Esquer a commencé d'éditer une fraction de ces mémoires dans une revue éphémère, l'Afrique française ${ }^{5}$; mais la publication intégrale qu'il annonçait n'a jamais vu le jour. $P$. Boyer le sait bien, puisque, dans son livre récent La vie quotidienne à Alger en 1830, il ne cite que mon édition.

Marcel Émerit, Faculte des lettres, Lille.

1. Voir Annales, mars-avril 1968, pp. 480-482.

2. L'état intellectuel et moral de l'Algérie en 1830 , Revue d'histoire moderne, juil.-sept. 1954, pp. 199-212 ; réédité dans la Revue des Travaúc de l'Académie des Sciences morales et politiques, 1954, $2^{\circ}$ semestre.

3. Oran, 24 décembre 1844. Arch. nat. $F^{30} 1675$.

4. L'Information historique, nov.-déc. 1963, no 4 , pp. 194 à 197.

5. M. Boyer pourrait au moins donner la référence : tome II, mai-sept. 1923, p. 28. 